\title{
Gluconic Acid Production from Golden Syrup by Aspergillus niger Strain Using Semiautomatic Stirred-Tank Fermenter
}

\author{
Nilesh K Purane ${ }^{1,2 *}$, Shital K Sharma ${ }^{1}$, Prajakta D Salunkhe ${ }^{3}$, Dinesh S Labade ${ }^{4}$ and Monali M Tondlikar ${ }^{5}$ \\ ${ }^{1}$ Bioprocessing \& Herbal Division, Mahatma Gandhi Institute for Rural Industrialization, Wardha-442 001, India \\ ${ }^{2}$ Department of Biotechnology, Kala Biotech, Pune, India \\ ${ }^{3}$ Department of Biotechnology, Lokamangal Biotechnology College, Solapur-413 222, India \\ ${ }^{4}$ Department of Biotechnology, Vidya Pratisthan's School of Biotechnology, Baramati-413 133, India \\ ${ }^{5}$ Department of Biotechnology, Kala Biotech, Pune-410 507, India
}

\begin{abstract}
The gluconic acid batch fermentation was conducted using mutant Aspergillus niger NCIM 530 strain under submerged condition in $50 \mathrm{~L}$ semiautomatic stirred-tank fermenter. Certain cost-effective source as golden syrup was effectively utilized instead of glucose for successful industrial fermentation process. The significant level of gluconic acid $\left(85.2 \mathrm{gL}^{-1}\right)$ production was observed with maximum $86.97 \%$ glucose conversion over 44 hours. This process provides great advantages over traditional submerged fermentation strategies and substrates, as showed by effective production of gluconic acid by utilizing novel substrate as a golden syrup. To reduce analysis time with better accuracy, an effort has been made to use a method for evaluation of parameters like conversion of substrate and production of gluconic acid during the fermentation by using High Performance Thin Layer Chromatography (HPTLC).
\end{abstract}

Keywords: Aspergillus niger; Golden syrup; Batch fermentation; Gluconic acid

\section{Introduction}

Gluconic Acid (GA) is a multifunctional carbonic acid belonging to bulk chemical, with outstanding properties, including extremely low toxicity, very low corrosiveness, and a capability of forming water soluble complexes with different metal ions. Due to these physiological and chemical properties, GA itself and its salts have found extensive demand in construction, chemicals, pharmaceuticals, food, beverage, textile, leather and other industries [1-3]. There are various approaches available for the production of gluconic acid namely, chemical, electrochemical, biochemical, bioelectrochemical, and photocatalytic approach [4-7]. Because of some limitation regarding these approaches, fermentation has been proved as efficient and dominant techniques for manufacturing GA. Most studied and widely used GA fermentation process involves filamentous fungus A. niger. Beside A. niger, other species such as A. terreus, Penicillium, Gliocadium, Scopulariopsis and Gonatabotrys have been tested and reviewed [8-10]. Several bacterial species including G. oxydans, G. diazotrophicus, Z. mobalis, A. methanolicus, P. florescens, and the species of Morexella, Tetracoccus, Pullularia, Micrococcus, Enterobacter and Scopulariopsis participate in GA production [9-11].

About 50,000-60,000 tons of GA is annually produced worldwide using glucose. However, use of GA and its derivatives is currently restricted because of high prices: about US\$ $1.20-8.50 / \mathrm{kg}$. Refined glucose and sucrose have been the main substrate for gluconic acid production $[12,13]$. The process could be further economized by replacing conventional refined carbohydrate material with more economical substrates. A large quantity of raw material produced in agriculture and industrial process can be utilized for gluconic acid production to minimize the fermentation cost. The various alternative carbohydrate sources were tested to make the GA fermentation process more economical as hydrol, corn starch, can molasses, grape must, banana must, food processing residues, figs, cheese whey, beet molasses, and saccharified solution of waste paper [14].

Golden syrup is a thick, amber-colour industrial by-product in form of inverted sugar syrup, made in the process of refining sugar cane juice into sugar, or by treatment of a sugar solution with acid. It contains nearly $47 \%$ glucose; so it can be effectively utilized for gluconic acid production. In present study the process of production of GA was economized by evaluating cheapest and optimum productive substrate golden syrup using isolated Aspergillus niger and demonstrates its role as reservoir in biotransformation of glucose in form of golden syrup to gluconic acid in submerged fermentation conditions.

\section{Material and Methods}

\section{Micro-organism}

In present work, mutant Aspergillus niger NCIM 530 derived from wild type Aspergillus niger NCIM 530 was provided by NCL Pune, India. During the study, this strain was maintained on agar slant of molasses medium at $30^{\circ} \mathrm{C}$ for 4 days.

\section{Harvesting of $A$. niger spores and inoculum preparation}

The spore of mutant $A$. niger from slant were harvested in $5 \mathrm{ml}$ of sterile $50 \mathrm{mM}$ sodium phosphate buffer ( $\mathrm{pH} 6.8$ ) containing $0.1 \%$ presterilized Tween 80 . The spores in inoculums were maintained at $10^{8}$ $-10^{10}$ spores per $\mathrm{ml}$. It was inoculated in erlenmeyer flasks containing spore germination medium with following composition: glucose $5 \%$, di-ammonium phosphate $0.2 \%, \mathrm{MgSO}_{4}, 0.25 \%, \mathrm{KH}_{2} \mathrm{PO}_{4} 0.1 \%$ (pH 5.5). The inoculated medium was put on orbital shaking incubator at $28^{\circ} \mathrm{C}$ with $180 \mathrm{rpm}$ for $48 \mathrm{hrs}$.

*Corresponding author: Nilesh K Purane, Department of Biotechnology, Kala Biotech, Pune-410 507 India, E-mail: npurane08@gmail.com

Received May 06, 2012; Accepted August 13, 2012; Published August 16, 2012

Citation: Purane NK, Sharma SK, Salunkhe PD, Labade DS, Tondlikar MM (2012) Gluconic Acid Production from Golden Syrup by Aspergillus niger Strain Using Semiautomatic Stirred-Tank Fermenter. J Microb Biochem Technol 4: 092-095. doi:10.4172/1948-5948.1000077

Copyright: (c) 2012 Purane NK, et al. This is an open-access article distributed under the terms of the Creative Commons Attribution License, which permits unrestricted use, distribution, and reproduction in any medium, provided the original author and source are credited 
Citation: Purane NK, Sharma SK, Salunkhe PD, Labade DS, Tondlikar MM (2012) Gluconic Acid Production from Golden Syrup by Aspergillus niger Strain Using Semiautomatic Stirred-Tank Fermenter. J Microb Biochem Technol 4: 092-095. doi:10.4172/1948-5948.1000077

\section{Fermenter equipment and resting cell culture system}

Batch fermentations were performed in $50 \mathrm{~L}$ semi-automatic stirred-tank fermenter (Scigenics Equipments, India) equipped with top stirred bearing three 6 blade ruston turbine type impellers, additionally four removable baffle plates attached to shell wall of fermenter. Agitation speed of stirred was set at $250 \mathrm{rpm}$. The temperature was constantly set at point $28^{\circ} \mathrm{C}$ using continuous water flow with thermostat. Fermentation medium with following composition (for $100 \mathrm{ml}$ of medium): golden syrup $21.28 \mathrm{ml}(10 \% \mathrm{w} / \mathrm{v}$ glucose concentration), di-ammonium phosphate $0.09 \mathrm{gm}, \mathrm{MgSO}_{4}$ $0.01 \mathrm{gm}$, Urea $0.015 \mathrm{gm}, \mathrm{KH}_{2} \mathrm{PO}_{4} 0.02 \mathrm{gm}$, olive oil $2 \mathrm{ml}$, distilled water $76.72 \mathrm{ml}$ (medium pH 5.5) sterilized at $12^{\circ} \mathrm{C}$ for 20 minutes with the help of steam air. The air saturation in fermenter was measured and controlled using polorographic dissolved oxygen probe. Before inoculation, $100 \%$ air saturation in sterilized fermenter medium was adjusted using the constant atmospheric air flow rate at 30 LPM. At same time, vessel pressure was maintained at 0.5 bars with the help of exhaust diaphragm valve. Sterilized fermentation medium was inoculated with $10 \% 48 \mathrm{hrs}$ old inoculums medium by using peristaltic pump. The $\mathrm{pH}$ was measured and maintained at set point 5.5 using gel filled, glass type $\mathrm{pH}$ probe, by automatically adding $15 \%$ pre-sterilized $\mathrm{CaCO}_{3}$ slurry. The sampling was carried out at regular interval from bottom fitted diaphragm valve.

\section{Determination of biomass, concentration of glucose and GA}

The dry fungal biomass was obtained after infiltration of broth sample though pre-weighted filter discs. The biomass was then washed with acidified distilled water, dried at $70^{\circ} \mathrm{C}$ and weighted [15].

The GA concentrations in samples were determined by measuring calcium in form of calcium gluconate (CG) in fermentation broth. The glucose and GA in fermentation samples were analyzed simultaneously by HPTLC (CAMAG, Ancrom Enterprises Pvt. Ltd, Mumbai). HPTLC was performed on $10 \mathrm{~cm} \times 20 \mathrm{~cm}$ pre-coated silica gel $\mathrm{GF}_{254}$ aluminum TLC plates (1.5554.0007, Merck KGaA, Germany). Plate was pre-washed with methanol: water with $4: 1(\mathrm{v} / \mathrm{v})$ ratio and activated by heating on CAMAG TLC plate heater on $100^{\circ} \mathrm{C}$ for one hour. Fermented broth samples and reference (Calcium gluconate-Acros Organics Germany; Glucose-Merk) were applied to the plated by means of CAMAG (Switzerland) Linomat V TLC applicator. The plate were developed at $30^{\circ} \mathrm{C} \pm 2^{\circ} \mathrm{C}$ to a distance of $8.5 \mathrm{~cm}$, with $20 \mathrm{~mL}$ of butanol : acetic acid : water with ratio 6:2:1 (v/v) as mobile phase, in CAMAG twin trough chamber. After removal from the chamber, plate was dried on CAMG TLC plate heater III for heating for half hour at $120^{\circ} \mathrm{C}$ (Figure 1 and 2). Plate was scanned and quantified at $310 \mathrm{~nm}$ with the help of CAMAG TLC Scanne 3 with WinCATS 1.4.4 software (Figure 3 and 4 ). The $\mathrm{R}_{\mathrm{f}}$ values of CG and glucose were 0.18 and 0.42 respectively.

The fermentation samples determination (Biomass, concentration of glucose and GA) were carried out in triplicate for reproducibility of results and it represented in form of mean. Statistical analysis was performed using ANOVA test software.

\section{Results and Discussion}

In present study, the mutant $A$. niger strain showed effective gluconic acid production with utilization of glucose in form of cheap carbohydrate source such as golden syrup (Figure 5 and 6). During batch fermentation, the initial glucose was maintained at $100 \mathrm{gL}^{-1}$. At initial residence time, GA production was increased very slowly (3.36
$\left.\mathrm{gL}^{-1}\right)$ with optimum productivity $\left(0.84 \mathrm{gL}^{-1} \mathrm{~h}^{-1}\right)$ rate over 4 hours. An increase in the levels of GA concentration $\left(12.33 \mathrm{gL}^{-1}\right)$ was observed over 24 hours with $0.51 \mathrm{gL}^{-1} \mathrm{~h}^{-1}$ productivity and further followed by rapid increase of GA production level $\left(34.75 \mathrm{gL}^{-1}\right)$ after 28 hours with $1.24 \mathrm{gL}^{-1} \mathrm{~h}^{-1}$ productivity and $38.8 \%$ glucose conversion. So, the period between 24 hours to 28 hours is considered as peak productivity period for GA. At the end of fermentation, maximum production of GA (85.2 $\left.\mathrm{gL}^{-1}\right)$ with highest productivity $\left(1.94 \mathrm{gL}^{-1} \mathrm{~h}^{-1}\right)$ was observed after 44 hours and showed $86.97 \%$ glucose conversion.

Several modified strategies in microbial fermentation conditions are often useful to improve product formation. Routine fermentation using naturally available microbial species under submerged conditions led to the development of the effective submerged fermentation process for GA production. This process is significantly affected by various factors. Among these, selection of suitable strain, substrate and process parameters are crucial. For significant GA production, $\mathrm{CaCO}_{3}$ is used as buffering agent during fermentation [10]. However, $\mathrm{CaCO}_{3}$ limits the possibility of obtaining high concentrations of product due to the

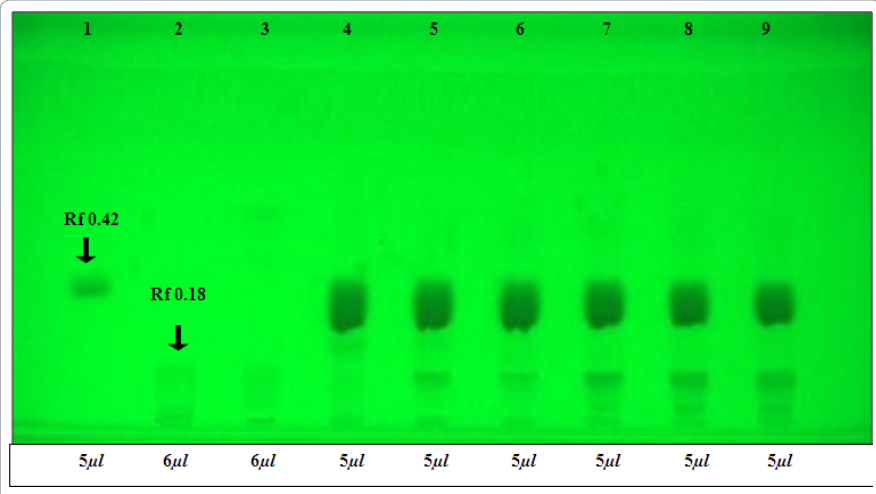

Track no $1=25 \mu \mathrm{g}$ std. glucose (Merk)

Track no $2=180 \mu \mathrm{g}$ std. calcium gluconate (Acros Organics, Germany)

Track no $3=6 \mu \mathrm{g}$ std. gluconic acid (Acros Organics, Germany)

Track no 4 to $9=4,8,12,16,20,24$ hours fermentation sample

Figure 1: HPTLC chromatogram of GA fermentation samples (4-24 hours) at UV $254 \mathrm{~nm}$.

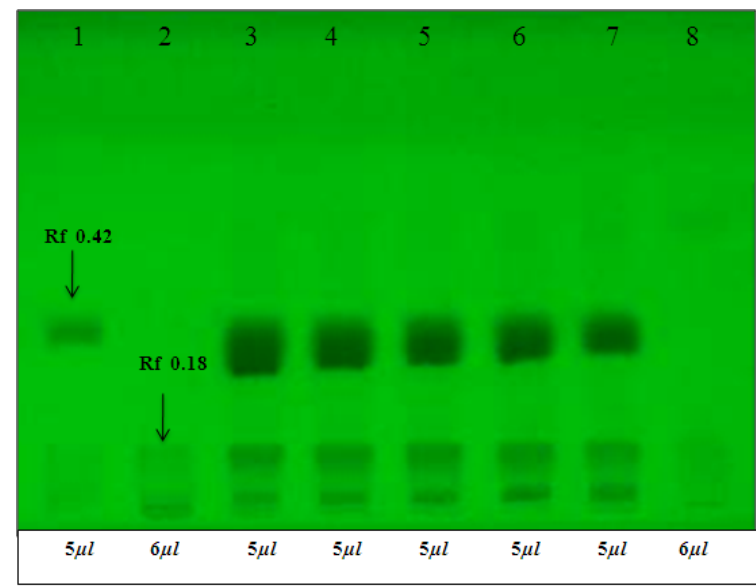

Track no $1=25 \mu \mathrm{g}$ std. glucose (Merk)

Track no $2=180 \mu \mathrm{g}$ std. calcium gluconate (Acros Organics, Germany) Track no 3 to $7=28,32,36,40 \& 44$ hours fermentation samples Track no $8=6 \mu \mathrm{g} / \mu \mathrm{l}$ std. gluconic acid (Acros Organics, Germany)

Figure 2: HPTLC chromatogram of GA fermentation samples (28-44 hours) at UV $254 \mathrm{~nm}$. 
limited solubility of the resulting calcium gluconate $\left(4 \%\right.$ at $\left.30^{\circ} \mathrm{C}\right)$ that precipitates over the mycelium thus inhibiting oxygen uptake [16]. To overcome this problem, substrate concentration was maintained up to $10 \%$. In the present batch fermentation, $\mathrm{CaCO}_{3}$ slurry $(15 \%)$ was continuously provided and maintained at constant $\mathrm{pH}$ (5.5) until the end of process. This was showed by increase volumetric productivity for GA production. Agitation increases the efficiency of aeration resulting in an increased interface between the gas and the liquid [17]. Because foaming affects on oxygen transfer rate from air and creates several problem in microbial aerobic fermentation, $2 \%$ olive oil was used as an antifoaming agent during fermentation [18].

Generally glucose is used as carbon source for microbial production of gluconic acid. Much research work on gluconic acid production has been done in cultures of $A$. niger using glucose as sole carbon source. For economical consideration of fermentation process, various types of alternative carbohydrate materials such as hydrol, corn starch, grape must, banana must, fig, cheese whey, food processing residues, and saccharified solution of waste paper were utilized in submerged and solid-state surface fermentation [19-24].

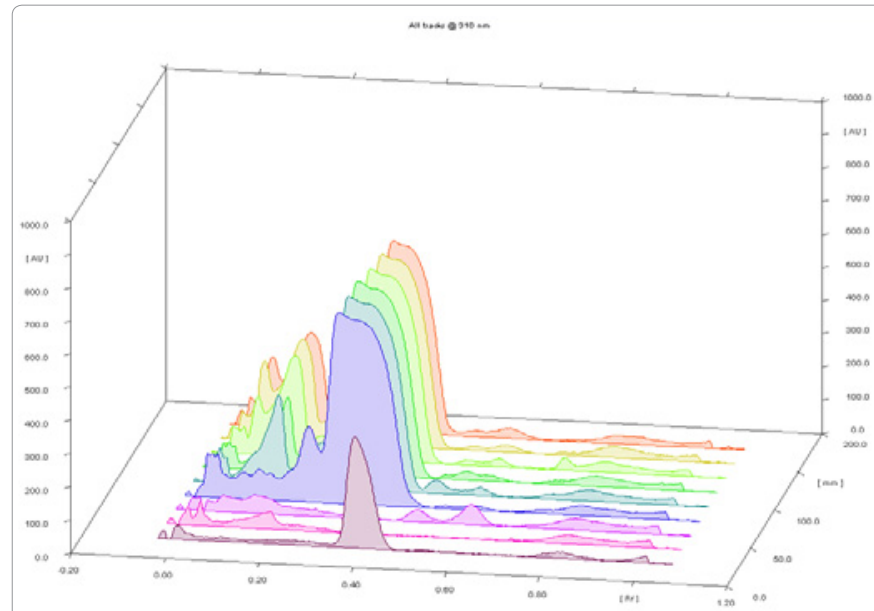

Figure 3: Densitogram curves of GA fermentation samples (4-24 hours) at 310 $\mathrm{nm}$.

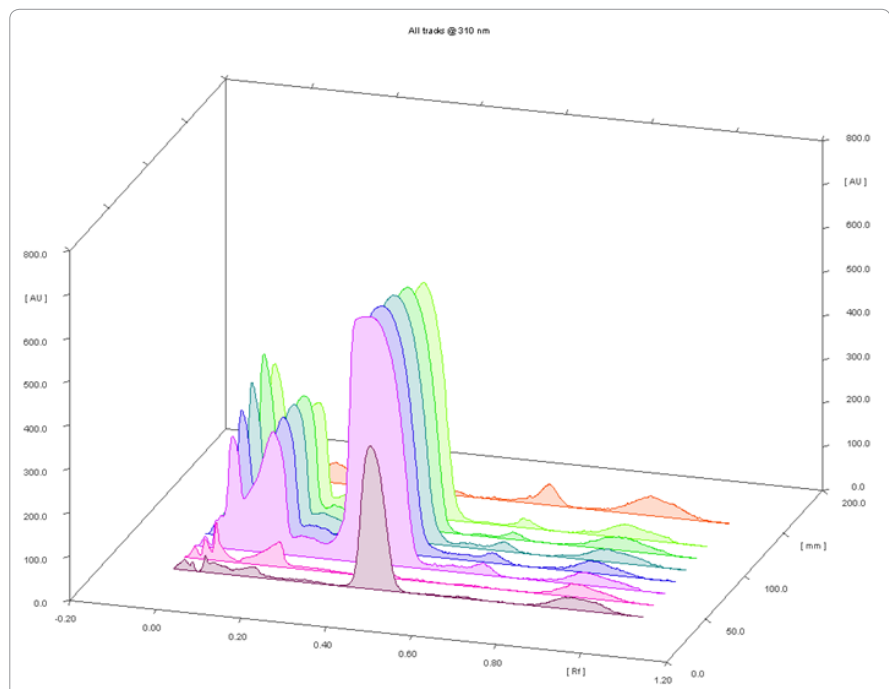

Figure 4: Densitogram curves GA fermentation samples (28-44 hours) at 310 $\mathrm{nm}$.

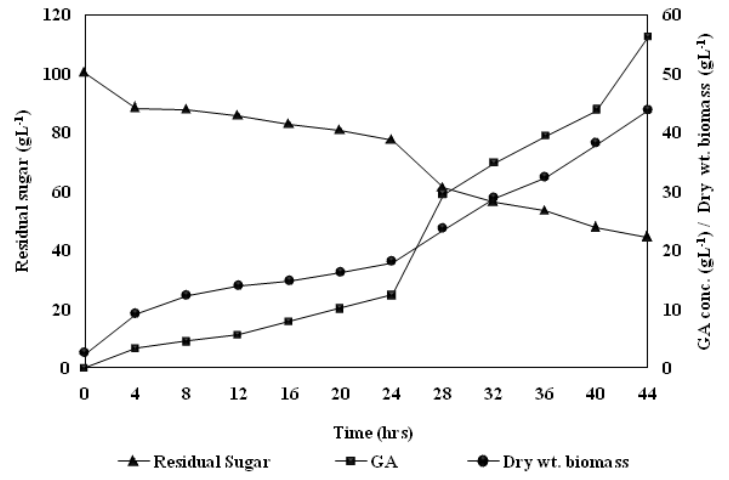

Figure 5: Time course changes of glucose, GA concentration and dry biomass weight during GA batch fermentation with $A$. niger.

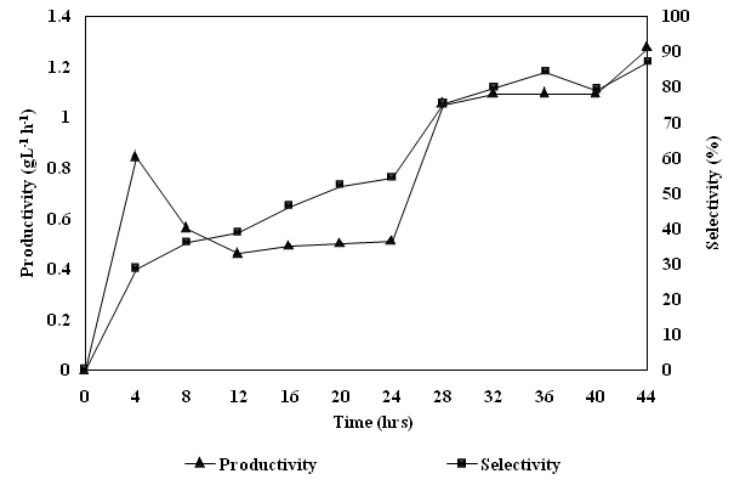

Figure 6: Time course changes of productivity, selectivity and yield during GA batch fermentation with $A$. niger.

Sing et al. [15] reported GA production by Aspergillus niger ORS4.410 using rectified grape must, banana must and treated molasses must under submerged fermentation, it showed GA production 73.2 $\mathrm{gL}^{-1}, 69.3 \mathrm{gL}^{-1}$ and $58.32 \mathrm{gL}^{-1}$ with product formation rate $0.509,0.481$ and 0.405 respectively [14]. Sapkal and Kulkarni (2002) reported GA production in a continuous recirculation reactor using immobilized $A$. niger on cellulose microfibers and obtained $158 \mathrm{~g} / \mathrm{l} \mathrm{GA}$ with $0.28 \mathrm{gL}^{-1} \mathrm{~h}^{-1}$ production rate [25]. They also immobilized A. niger on cellulose and obtained $135 \mathrm{gL}^{-1}$ of GA with $0.09 \mathrm{gL}^{-1} \mathrm{~h}^{-1}$ productivity rate in surface culture [26]. The scientist attempted utilization of waste paper for GA production as $80-100 \mathrm{gL}^{-1}$ achieved with $0.04 \mathrm{gL}^{-1} \mathrm{~h}^{-1}$ productivity [14]. The kinetic analysis of gluconic acid production by $A$. niger mutant ORS-4.410 indicated that fermentation of glucose results in $94.5 \%$ yield after 144 hours of incubation [27]. This paper represents first experiment using raw golden syrup as glucose containing substrate for GA fermentation in semi automatic PLC based bioreactor using mutant A. niger NCIM 530 strain. It showed average yield of GA $85.20 \mathrm{gL}^{-1}$ over 44 hours with $1.94 \mathrm{gL}^{-1} \mathrm{~h}^{-1}$ productivity. However it is apparent that pure glucose was the better carbon source resulting high yield of GA as compared to golden syrup. Because, presence of complex carbohydrate residual material (remaining unconverted starch, other glucose etc) or some impurity in golden syrup may retard mutant $A$. niger NCIM 530 to favor the GA production.

To obtain high level of GA production a sufficient level of pure oxygen supply is indispensible $[28,29]$. However, in present study pure form of air supply were used during fermentation process. Higher 
Citation: Purane NK, Sharma SK, Salunkhe PD, Labade DS, Tondlikar MM (2012) Gluconic Acid Production from Golden Syrup by Aspergillus niger Strain Using Semiautomatic Stirred-Tank Fermenter. J Microb Biochem Technol 4: 092-095. doi:10.4172/1948-5948.1000077

productivity may have been obtained if a sufficient level of pure oxygen supply.

In GA fermentation process, analysis of fermented samples has importance for evaluation of microbial process including GA concentration, yield determination, productivity etc. Many researchers used HPLC or enzymatic spectrophotometric method for analysis of gluconic acid. However, these methods are costly and time consuming. We made effort to develop the HPTLC method for analysis of GA and glucose during fermentation process. This saves cost per analysis and analysis time as well. It also facilitates repeated detection (scanning) of the chromatogram with same or different parameter. It has main advantage to analyse both glucose and GA concentration of many sample (nearly 15 samples) in single step with better accuracy.

Economical feasibility is of prime importance for any industry significant product formation to be viable and successful, and to a greater extent depends on selection of substrate for fermentation process. In addition, the proper fermentation conditions are needed to improve product formation during microbial fermentation. The present work made attempt to obtain optimum GA production with minimum residence time by using novel carbohydrate sources as golden syrup in replacement of glucose during submerged fermentation, but process still needs some experimentation and improvement. It may be possible to establish effective strategies such as substrate clarification, continuous GA fermentation and simultaneous recovery of GA.

\section{Acknowledgement}

We take this opportunity to express our sincere thanks and gratitude Dr. A.K. Agnihotri and Dr. Karm Raj Yadav for their valuable guidance and help. Finally we acknowledge with deep appreciation, the indispensable help, encouragement and moral support received from our colleague and dear ones.

\section{References}

1. Hustede H, Haberstroh HJ, Schinzig E (2000) Gluconic acid: Ullmann's Encyclopedia of Industrial Chemistry.

2. Anastassiadis S, Aivasidis A, Wandrey C (2003) Continuous gluconic acid production by isolated yeast-like mould strains of Aureobasidium pullulans. Appl Microbiol Biotechnol 61: 110-117.

3. Znad H, Markos J, Bales V (2004) Production of gluconic acid from glucose by Aspergillus niger: growth and non-growth conditions. Process Biochem 39: 1341-1345.

4. Isbell HS, Frush HL, Bates FJ (1932) Manufacture of Calcium Gluconate by Electrolytic Oxidation of Glucose. Ind Eng Chem 24: 375-378

5. Pfizer C (1952) Improvements in or relating to the preparation of resinous materials and polymerizable compositions for producing the same.

6. De Wilt HGJ (1972) Oxidation of glucose to gluconic acid. Ind Eng Prod Res Dev 11: $370-378$

7. Colmenares JC, Magdziarz A, Bielejewska A (2011) High-value chemicals obtained from selective photo-oxidation of glucose in the presence of nanostructured titanium photocatalysts. Bioresour Technol 11254-11257.

8. Dowdells C, Jones RL, Mattey M, Bencina M, Legisa M, et al. (2010) Gluconic acid production by Aspergillus terreus. Lett Appl Microbiol 252-257.

9. Milson PE, Meers JL (1985) Gluconic acid, Itaconic acid: In Blanch HW, Drew $S$ (edn.) Comprehensive biotechnology. Wang DIC.

10. Ramachandran S, Fontanille P, Pandey A, Larroche C (2006) Gluconic Acid: Properties, Applications and Microbial Production. Food Technol Biotechnol 44: 185-195

11. Crespo JM, Boiardi JL, Luna MF (2011) Mineral phosphate solubilization activity of Gluconacetobacter diazotrophicus under P-limitation and plant root environment. Agricultural Sciences 2: 16-22.

12. Ray S, Banik AK (1994) Development of a mutant strain of Aspergillus niger and optimization of some physical factors for improved calcium gluconate production. Indian J Exp Biol 32: 865-868.
13. Silveira MM, Wisbeck E, Lemmel C, Erzinger G, da Costa JP, et al. (1999) Bioconversion of glucose and fructose to sorbitol and gluconic acid by untreated cells of Zymomonas mobilis. J Biotechnol 75: 99-103.

14. Singh OV, Kumar R (2007) Biotechnological production of gluconic acid: future implications. Appl Microbiol Biotechnol 75: 713-722.

15. Singh OV, Kapur N, Singh RP (2005) Evaluation of agro-food byproducts for gluconic acid production by Aspergillus niger ORS-4.410. World J Microbiol Biotechnol 21: 519-524.

16. Moresi M, Parente E, Ricciardi A, Lanorte M (1996) Effect of dissolved oxygen concentration on $\mathrm{pH}$-controlled fed-batch gluconate production by immobilised Aspergillus niger. Progress in Biotechnology 11: 370-378.

17. Zetelaki KZ (1970) The role of aeration and agitation in the production of glucose oxidase in submerged culture. II. Biotechnol Bioeng 12: 379-397.

18. Purane N, Shinde M, Sharma S, Mahajani S (2011) Effect of nutrient additives on gluconic acid production by $A$. niger during submerged fermentation. J pure and Appl Microbiol 5: 235-239.

19. Roukas T, Harvey $L$ (1988) The effect of $\mathrm{pH}$ on production of citric acid and gluconic acid from beet molasses using continuous culture. Biotechnol Lett 10 289-294.

20. Buzzini P, Gobbetti M, Rossi J, Ribaldi M (1993) Utilization of grape must and concentrated rectified grape must to produce gluconic acid by Aspergillus niger, in batch fermentations. Biotechnol Lett 15: 151-156.

21. Roukas T (2000) Citric and gluconic acid production from fig by Aspergillus niger using solid-state fermentation. J Ind Microbiol Biotechnol 25: 298-304.

22. Mukhopadhyay R, Chatterjee S, Chatterjee BP, Banerjee PC, Guha AK (2005) Production of gluconic acid from whey by free and immobilized Aspergillus niger. Int Dairy J 15: 299-303.

23. Ikeda Y, Park EY, Okuda N (2006) Bioconversion of waste office paper to gluconic acid in a turbine blade reactor by the filamentous fungus Aspergillus niger. Bioresour Technol 97: 1030-1035.

24. Singh OV, Singh RP (2006) Bioconversion of grape must into modulated gluconic acid production by Aspergillus niger ORS-4.410. J Appl Microbiol 100: 1114-1122.

25. Sankpal NV, Kulkarni BD (2002) Optimization of fermentation conditions for gluconic acid production using Aspergillus niger immobilized on cellulose microfibrils. Process Biochem 37: 1343-1350.

26. Sankpal NV, Joshi AP, Sutar II, Kulkarni BD (1999) Continuous production of gluconic acid by Aspergillus niger immobilized on a cellulosic support: study of low pH fermentative behaviour of Aspergillus niger. Process Biochem 35 317-325.

27. Singh OV, Sharma A, Singh RP (2001) Optimisation of fermentation conditions for gluconic acid production by a mutant of Aspergillus niger. Indian J Exp Biol 39: $1136-1143$

28. Sakurai H, Lee HW, Sato S, Mukataka S, Takahashi J (1989) Gluconic acid production at high concentrations by Aspergillus niger immobilized on a nonwoven fabric. J Ferment Bioeng 67: 404-408.

29. Klein J, Rosenberg M, Markos J, Dolgo s O, Kro s lak M, Kri s tofíkova L (2002) Biotransformation of glucose to gluconic acid by Aspergillus niger -study of mass transfer in an airlift bioreactor. Biochem Eng J 10: 197-205. 